\title{
Canadian Political Science Association / Association canadienne de science politique
}

President/président

Tom Pocklington

University of Alberta

Past President/présidente sortante Jane Jenson

Université de Montréal

President Elect/président élu

Donald Savoie

Université de Moncton

Secretary-Treasurer/secrétaire-trésorier

F. Leslie Seidle

Privy Council Office

c/o CPSA / a/s ACSP

\#205-1, ne Stewart Street

Ottawa, Ontario K1N $6 \mathrm{H} 7$

Representative of Members-at-Large/

représentante des conseillers(ères)

Elisabeth Gidengil

McGill University

Members-at-large/Conseillers(ères)

2-year term/mandat de deux ans:

Andrew Cooper (Waterloo), A. Claire Cutler (Victoria), Anne-Marie Gingras (Laval),

Neil Nevitte (Toronto), Ian Stewart (Acadia)

I-year term/mandat d'un an :

Elisabeth Gidengil (McGill), Janet Hiebert

(Queen's), Raymond Hudon (Laval),

William Mathie (Brock), Hans Michelmann

(Saskatchewan)

Nominating Committee/Comité des candidatures 1998

Tom Pocklington (Alberta), Chair/Président,

Lynda Erickson (Simon Fraser), Margaret

Moore (Waterloo), Alain Noël (Montréal)
Other positions/autres positions

Christopher P. Manfredi (McGill), Co-editor of the Journal

François Rocher (Carleton), codirecteur de la Revue

John McMenemy (Wilfrid Laurier), Administrative Editor of the Journal/directeur administratif de la Revue

François Houle, Chair, Programme Committee/président du Comité d'organisation du programme (1998)

Clinton Archibald (Ottawa), Director/ directeur, Parliamentary Internship Programme/Programme de stage parlementaire

Robert J. Williams (Waterloo), Director/directeur, Ontario Legislature Internship Programme/Programme de stage à l'Assemblée legislative de l'Ontario

J. Peter Meekison, Chair, Trust Fund/ président, Fonds de prévoyance

Claire Turenne Sjolander (Ottawa), Coeditor/codirectrice du Bulletin

Gilles Labelle (Ottawa), Co-editor/codirecteur du Bulletin

Louis Balthazar (Laval), représentant de la Société québécoise de science politique

Andrew Cooper (Waterloo), Representative to HSSFC/représentant à la FCSHS

Michelle Hopkins, Executive Secretary / secrétaire administrative

\section{Gुी Société québécoise de science politique}

Président, Louis Balthazar (Laval)

Président sortant, Guy Lachapelle (Concordia)

Vice-présidente, Micheline de Sève (UQAM)

Secrétaire

Guy Bédard

Département de science politique Université du Québec à Montréa!

C.P. 8888, succ. Centre-Ville

Montréal, QC H3C 3P8

Trésorier

Robert Dalpé

Département de science politique

Université de Montréal

C.P. 6128, succ. Centre-Ville

Montréal, QC H3C 3J7
Autres membres du Conseil d'administration Nicole Bernier (Montréal), Gilles Labelle (Ottawa), Chantal Maillé (Concordia), Michel Fortmann (Montréal), Bernard Fournier (INRS-Culture et Sociétés), Pierre Noreau (UQAT), Yves Boisvert (INRS-Culture et Sociétés)

\section{Invité(e)s}

François Rocher (Carleton), codirecteur de la Revue canadienne de science politique

Alain-G. Gagnon (McGill), directeur de la revue Politique et Sociétés

F. Leslie Seidle (Bureau du Conseil Privé), représentant de l'Association canadienne de science politique

Élaine Dupré, agente d'administration 